From the Clinical Research Division, Fred Hutchinson Cancer Research Center; University of Washington School of Medicine; Children's Hospital and Regional Medical Center; Veterans Affairs Puget Sound Health Care System, Seattle, WA; and Department of Hematology, University of Liège, Liège, Belgium.

Submitted August 26, 2004; accepted December 14, 2004

Supported by grant Nos. CA78902, HL36444, CA18029, CA92058, DK064715, and CA15704 from the National Institutes of Health, Department of Health and Human Services, Bethesda, MD. R.S. received support from the Laura Landro Salomon Endow ment Fund. F.B. is a research associate of the National Fund for Scientific Research, Belgium, and is supported in part by postdoctoral grants from the

Fulbright Commission.

F.B. and M.B.M. contributed equally to this work.

Authors' disclosures of potential conflicts of interest are found at the end of this article.

Address reprint requests to Rainer Storb, MD, Fred Hutchinson Cancer Research Center, 1100 Fairview Ave N D1-100, PO Box 19024, Seattle, WA 98109-1024; e-mail: rstorb@fhcrc.org

(C) 2005 by American Society of Clinical Oncology

0732-183X/05/2309-1993/\$20.00

DOI: $10.1200 / J C O .2005 .08 .136$

\title{
Graft-Versus-Tumor Effects After Allogeneic Hematopoietic Cell Transplantation With Nonmyeloablative Conditioning
}

Frédéric Baron, Michael B. Maris, Brenda M. Sandmaier, Barry E. Storer, Mohamed Sorror, Razvan Diaconescu, Ann E. Woolfrey, Thomas R. Chauncey, Mary E.D. Flowers, Marco Mielcarek, David G. Maloney, and Rainer Storb

$$
\begin{array}{llllllll}
\text { A } & \text { B } & \text { S } & \text { T } & \text { R } & \text { A } & \text { C } & \text { T }
\end{array}
$$

\section{Purpose}

We have used a nonmyeloablative conditioning regimen consisting of total-body irradiation (2 Gy) with or without fludarabine (30 mg/m²/ for 3 days) for related and unrelated hematopoietic cell transplantation $(\mathrm{HCT})$ in patients with hematologic malignancies who were not candidates for conventional HCT because of age, medical comorbidities, or preceding high-dose HCT. This approach relied on graft-versus-tumor (GVT) effects for control of malignancy.

\section{Patients and Methods}

We analyzed GVT effects in 322 patients given grafts from HLA-matched related ( $n=192$ ) or unrelated donors ( $n=130$ ).

\section{Results}

Of the 221 patients with measurable disease at HCT, $126(57 \%)$ achieved complete $(n=98)$ or partial ( $n=28$ ) remissions. In multivariate analysis, there was a higher probability trend of achieving complete remissions in patients with chronic extensive graft-versus-host disease (GVHD; $P=.07$ ). One hundred eight patients (34\%) relapsed or progressed. In multivariate analysis, achievement of full donor chimerism was associated with a decreased risk of relapse or progression ( $P=.002$ ). Grade 2 to 4 acute GVHD had no significant impact on the risk of relapse or progression but was associated with increased risk of nonrelapse mortality and decreased probability of progression-free survival (PFS). Conversely, extensive chronic GVHD was associated with decreased risk of relapse or progression $(P=.006)$ and increased probability of PFS $(P=.003)$.

\section{Conclusion}

New approaches aimed at reducing the incidence of grade 2 to 4 acute GVHD might improve survival after allogeneic HCT after nonmyeloablative conditioning.

\section{J Clin Oncol 23:1993-2003. (C) 2005 by American Society of Clinical Oncology}

\section{INTRODUCTION}

It was recognized as early as 1956 that transplanted allogeneic immunocompetent cells could eliminate leukemic cells in mice independent of chemoradiotherapy. ${ }^{1}$ This was termed a graft-versus-tumor (GVT) effect. $^{2,3}$ Initial evidence for GVT effects in humans came from studies reporting reduced leukemic relapse rates in allografted patients who developed acute and/or chronic graft-versus-host disease (GVHD) compared with patients who did not. ${ }^{2,3}$ GVT effects were confirmed by other investigators who observed increased risks of relapse in patients receiving $\mathrm{T}$-cell-depleted $^{4}$ and syngeneic transplantations. ${ }^{5}$ Direct support for antitumor effects of allogeneic cells came from observations that donor lymphocyte infusions (DLI) could induce complete remissions in some patients with hematologic malignancies who 


\begin{tabular}{|c|c|c|c|c|c|c|}
\hline \multirow[b]{2}{*}{ Characteristic } & \multicolumn{2}{|c|}{$\begin{array}{l}\text { All Patients } \\
(\mathrm{N}=322)\end{array}$} & \multicolumn{2}{|c|}{$\begin{array}{l}\text { Related } \\
\text { Recipients } \\
(\mathrm{n}=192)\end{array}$} & \multicolumn{2}{|c|}{$\begin{array}{l}\text { Unrelated } \\
\text { Recipients } \\
(\mathrm{n}=130)\end{array}$} \\
\hline & No. & $\%$ & No. & $\%$ & No. & $\%$ \\
\hline \multicolumn{7}{|l|}{ Patient age, years } \\
\hline Median & \multicolumn{2}{|c|}{54} & \multicolumn{2}{|c|}{54} & \multicolumn{2}{|c|}{54} \\
\hline Range & \multicolumn{2}{|c|}{$5-72$} & \multicolumn{2}{|c|}{$21-72$} & \multicolumn{2}{|c|}{$5-71$} \\
\hline \multicolumn{7}{|l|}{ Recipient sex } \\
\hline Male & 207 & 64 & 122 & 64 & 85 & 65 \\
\hline Female & 115 & 35 & 70 & 36 & 45 & 35 \\
\hline \multicolumn{7}{|l|}{ Donor age, years } \\
\hline Median & \multicolumn{2}{|c|}{46} & \multicolumn{2}{|c|}{52} & \multicolumn{2}{|c|}{34} \\
\hline Range & & & & & & \\
\hline Donor sex & & & & & & \\
\hline Male & 167 & 52 & 90 & 47 & 77 & 59 \\
\hline Female & 155 & 48 & 102 & 53 & 53 & 41 \\
\hline Female donor/male recipient & 94 & 29 & 64 & 33 & 31 & 24 \\
\hline Diagnosis/status before allogeneic HCT & & & & & & \\
\hline Acute myeloid leukemia & & & & & & \\
\hline CR 1 & 15 & 4.7 & 11 & 5.7 & 4 & 3.1 \\
\hline$C R>2$ & 27 & 8.4 & 9 & 4.7 & 18 & 13.8 \\
\hline Not in $\mathrm{CR}$ & 4 & 1.2 & 2 & 1.0 & 2 & 1.5 \\
\hline Acute lymphoblastic leukemia & & & & & & \\
\hline CR 1 & 5 & 1.6 & 0 & 0.0 & 5 & 3.8 \\
\hline$>$ CR 1 & 5 & 1.6 & 1 & 0.5 & 4 & 3.1 \\
\hline Chronic myeloid leukemia & & & & & & \\
\hline $\mathrm{CP} 1$ & 11 & 3.4 & 4 & 2.1 & 7 & 5.4 \\
\hline $\mathrm{CP} 2$ & 3 & 0.9 & 1 & 0.5 & 2 & 1.5 \\
\hline$>\mathrm{CP}$ & 4 & 1.2 & 2 & 1.0 & 2 & 1.5 \\
\hline Chronic lymphocytic leukemia & & & & & & \\
\hline CR & 1 & 0.3 & 0 & 0.0 & 1 & 0.8 \\
\hline PR & 5 & 1.6 & 4 & 2.1 & 1 & 0.8 \\
\hline$>\mathrm{PR}$ & 28 & 8.7 & 20 & 10.4 & 8 & 6.2 \\
\hline Myelodysplastic syndrome & & & & & & \\
\hline $\mathrm{RA} / \mathrm{CR}^{*}$ & 32 & 10.0 & 17 & 8.9 & 15 & 11.5 \\
\hline$>\mathrm{RA}$ & 13 & 4.0 & 8 & 4.2 & 5 & 3.8 \\
\hline Multiple myeloma & & & & & & \\
\hline $\mathrm{CR}$ & 6 & 1.9 & 6 & 3.1 & 0 & 0.0 \\
\hline MRD & 16 & 5.0 & 15 & 7.8 & 1 & 0.8 \\
\hline $\mathrm{PR}$ & 21 & 6.5 & 15 & 7.8 & 6 & 4.6 \\
\hline$>\mathrm{PR}$ & 21 & 6.5 & 16 & 8.3 & 5 & 3.8 \\
\hline Non-Hodgkin's lymphoma & & & & & & \\
\hline $\mathrm{CR}$ & 19 & 5.9 & 12 & 6.3 & 7 & 5.4 \\
\hline PR & 19 & 5.9 & 15 & 7.8 & 4 & 3.1 \\
\hline$>\mathrm{PR}$ & 30 & 9.3 & 16 & 8.3 & 14 & 10.8 \\
\hline Hodgkin's disease & & & & & & \\
\hline CR & 1 & 0.3 & 0 & 0.0 & 1 & 0.8 \\
\hline PR & 6 & 1.9 & 4 & 2.1 & 2 & 1.5 \\
\hline$>P R$ & 16 & 5.0 & 7 & 3.6 & 9 & 6.9 \\
\hline Myeloproliferative syndrome other than chronic myeloid leukemia & 10 & 3.1 & 4 & 2.1 & 6 & 4.6 \\
\hline Waldenström's macroglobulinemia & 4 & 1.2 & 3 & 1.6 & 1 & 0.8 \\
\hline Disease risks $\dagger^{-}$ & & & & & & \\
\hline Standard risk & 153 & 47.5 & 101 & 52.6 & 52 & 40.0 \\
\hline High risk & 144 & 44.7 & 77 & 40.1 & 67 & 51.5 \\
\hline Very high risk & 25 & 7.8 & 14 & 7.3 & 11 & 8.5 \\
\hline Tumor chemosensitivity $\ddagger$ & & & & & & \\
\hline Yes & 110 & - & 82 & - & 28 & - \\
\hline No & 80 & - & 49 & - & 31 & - \\
\hline Unknown & 3 & - & 2 & - & 1 & - \\
\hline Measurable disease at HCT & 221 & 68.6 & 143 & 74.5 & 78 & 60.0 \\
\hline (contin & ollowir & & & & & \\
\hline
\end{tabular}




\begin{tabular}{|c|c|c|c|c|c|c|}
\hline \multirow[b]{2}{*}{ Characteristic } & \multicolumn{2}{|c|}{$\begin{array}{l}\text { All Patients } \\
(\mathrm{N}=322)\end{array}$} & \multicolumn{2}{|c|}{$\begin{array}{c}\text { Related } \\
\text { Recipients } \\
(\mathrm{n}=192)\end{array}$} & \multicolumn{2}{|c|}{$\begin{array}{l}\text { Unrelated } \\
\text { Recipients } \\
(\mathrm{n}=130)\end{array}$} \\
\hline & No. & $\%$ & No. & $\%$ & No. & $\%$ \\
\hline \multicolumn{7}{|l|}{ Conditioning regimen } \\
\hline TBI only & 75 & 23.3 & 75 & 39.0 & 0 & 0 \\
\hline $\mathrm{TBI}+$ fludarabine & 247 & 76.7 & 117 & 61.0 & 130 & 100 \\
\hline Tandem autologous-allogeneic HCT & 59 & 18.3 & 54 & 28.1 & 5 & 3.8 \\
\hline Failed previous myeloablative $\mathrm{HCT}$ & 87 & 27.0 & 36 & 18.8 & 51 & 39.2 \\
\hline \multicolumn{7}{|l|}{ Charlson comorbidity index } \\
\hline Score 0 & 151 & 46.9 & 92 & 47.9 & 59 & 45.4 \\
\hline Score 1-2 & 126 & 39.1 & 77 & 40.1 & 49 & 37.7 \\
\hline Score $>2$ & 29 & 9.0 & 11 & 5.7 & 18 & 13.8 \\
\hline Unknown & 16 & 5.0 & 12 & 6.3 & 4 & 3.1 \\
\hline \multicolumn{7}{|l|}{ Donor } \\
\hline HLA-identical & 296 & 91.9 & 187 & 97.4 & 109 & 83.8 \\
\hline 1 antigen HLA mismatch & 16 & 5.0 & 5 & 2.6 & 11 & 8.5 \\
\hline 1 allele HLA mismatch & 10 & 3.1 & 0 & 0 & 10 & 7.7 \\
\hline \multicolumn{7}{|l|}{ Stem-cell source } \\
\hline G-PBMC & 308 & 95.7 & 192 & 100 & 116 & 89.2 \\
\hline Marrow & 14 & 4.3 & 0 & 0 & 14 & 10.8 \\
\hline \multicolumn{7}{|l|}{ Cell dose, $\times 10^{6} / \mathrm{kg}$ recipient } \\
\hline \multicolumn{7}{|l|}{ CD34+ cells } \\
\hline Median & \multicolumn{2}{|c|}{7.8} & \multicolumn{2}{|c|}{9.4} & \multicolumn{2}{|c|}{6.5} \\
\hline Range & \multicolumn{2}{|c|}{$0.8-42.7$} & \multicolumn{2}{|c|}{$1.7-42.7$} & \multicolumn{2}{|c|}{$0.8-26.0$} \\
\hline \multicolumn{7}{|l|}{ T cells } \\
\hline Median & \multicolumn{2}{|c|}{304} & \multicolumn{2}{|c|}{346} & \multicolumn{2}{|c|}{248} \\
\hline Range & \multicolumn{2}{|c|}{$16-934$} & \multicolumn{2}{|c|}{$47-760$} & \multicolumn{2}{|c|}{$16-934$} \\
\hline \multicolumn{7}{|l|}{ Follow-up for alive patients, months } \\
\hline Median & \multicolumn{2}{|c|}{23} & \multicolumn{2}{|c|}{27} & \multicolumn{2}{|c|}{18} \\
\hline Range & \multicolumn{2}{|c|}{ 3-72 } & & & \multicolumn{2}{|c|}{$3-49$} \\
\hline \multicolumn{7}{|c|}{$\begin{array}{l}\text { Abbreviations: HCT, hematopoietic cell transplantation; CR, complete remission; PR, partial remission; CP, chronic phase; RA, refractory anemia; MRD, } \\
\text { minimal residual disease; TBI, total-body irradiation; G-PBMC, granulocyte colony-stimulating factor-mobilized peripheral-blood mononuclear cells; RAEB, } \\
\text { refractory anemia with excess blasts; RAEBT, refractory anemia with excess blasts in transformation; AML, acute myeloid leukemia. } \\
\text { "Including patients who received chemotherapy for RAEB, RAEBT, or AML now either in CR or in RA. } \\
\text { tStandard risks were defined as acute myeloid leukemia in first complete remission, acute lymphoblastic leukemia in first complete remission, } \\
\text { myelodysplastic syndrome-refractory anemia, chronic myeloid leukemia in first chronic phase, chronic lymphocytic leukemia, low-grade non-Hodgkin's } \\
\text { lymphoma, high- or intermediate-grade non-Hodgkin's lymphoma in complete remission, Hodgkin's disease in complete remission, and multiple myeloma in } \\
\text { complete remission or with minimal residual disease; very high risks were defined as acute leukemia above second complete remission, chronic myeloid } \\
\text { leukemia in accelerated phase or blast crisis and myelodysplastic syndrome-refractory anemia with blast excess or above; all other diagnoses were classified } \\
\text { as high risk. } \\
\text { fRestricted to patients with chronic lymphocytic leukemia, lymphomas, multiple myeloma, and Waldenström's disease. }\end{array}$} \\
\hline
\end{tabular}

had relapsed after allogeneic hematopoietic cell transplantation (HCT). ${ }^{6-8}$

The use of recently introduced reduced-intensity ${ }^{9-15}$ and truly nonmyeloablative conditioning regimens ${ }^{16-22}$ has shifted some or all of the burden of tumor-cell kill from the conditioning regimens to the GVT effects. These regimens are less toxic than conventional regimens and allow for treatment of older patients and patients with comorbid conditions. ${ }^{23,24}$

Here, we analyzed GVT effects in 322 patients with various hematologic malignancies given grafts from HLAmatched related or unrelated donors after a nonmyeloablative regimen consisting of total-body irradiation (TBI; 2 Gy) with or without fludarabine $\left(30 \mathrm{mg} / \mathrm{m}^{2} / \mathrm{d}\right.$ for 3 days) and postgrafting immunosuppression with mycopheno- late mofetil (MMF) and cyclosporine (CSP). This is the first large series evaluating a relationship between acute and chronic GVHD and GVT responses after nonmyeloablative conditioning.

\section{PATIENTS AND METHODS}

\section{Patients}

Table 1 lists the data from 322 consecutive patients with hematologic malignancies administered allogeneic HCT after nonmyeloablative conditioning at the Fred Hutchinson Cancer Research Center, the University of Washington Medical Center, the Children's Hospital and Regional Medical Center, and the Veterans Affairs Puget Sound Health Care System (all in Seattle, WA) on prospective multicenter research protocols between 


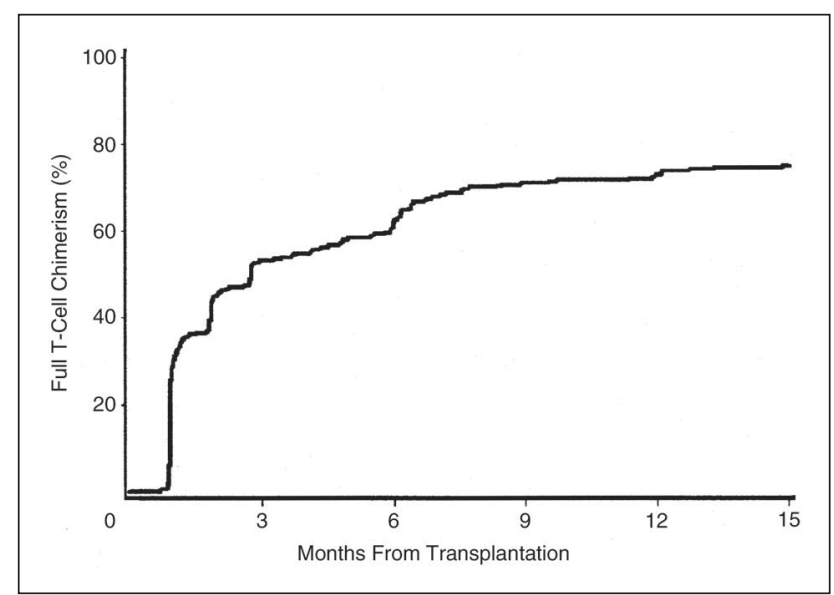

Fig 1. Cumulative incidence of achieving full donor T-cell chimerism.

November 1998 and December 2003. Here, we analyzed the data retrospectively for GVT effects as of March 31, 2004. To assure consistent grading and treatment of acute and chronic GVHD, only patients treated in Seattle were included in this analysis. Patients were considered ineligible for conventional allogeneic HCT because of age and/or comorbidities or preceding high-dose HCT. ${ }^{17,20,25}$ For patients in good medical condition with chronic myeloid leukemia (CML) in first chronic phase, myelodysplastic syndrome (MDS), and acute myeloid leukemia (AML) in first complete remission, the age cutoff was 65 years with sibling grafts and 50 years with unrelated grafts. For patients in good medical condition with B-cell malignancies, the age cutoff was 50 years regardless of stem-cell source. Patients who had experienced failure with high-dose HCT and patients with comorbid conditions underwent nonmyeloablative HCT, even if they were younger than the age cutoffs. Characteristics of the patients are listed in Table 1. Median follow-up after HCT was 23 months (range, 3 to 72 months).

Median patient age was 54 years (range, 5 to 72 years). Sixty percent of patients received grafts from related donors, and $40 \%$ received grafts from unrelated donors. Stem-cell sources were granulocyte colony-stimulating factor-mobilized peripheral- blood mononuclear cells (G-PBMC) in 308 patients and marrow in 14 patients; the latter patients were all recipients of unrelated grafts. Patients were classified as being at standard risk, high risk, or very high risk of progression, as described in Table 1.

Compatibility between patients and donors for HLA-A, -B, and $-\mathrm{C}$ antigens was assessed by intermediate-resolution DNA typing to a level at least as sensitive as serology, and compatibility between patients and donors for HLA-DRB1 and HLADQB1 was assessed by high-resolution techniques. ${ }^{26}$ Two hundred ninety-six patients received grafts from HLA-matched donors, 16 grafts were from donors mismatched for a single class I HLA antigen (seven of these donors also had one additional mismatch at the allele level), and 10 grafts were from donors mismatched for one HLA class I allele.

Pretransplantation comorbidities were determined from the patients' pretransplantation evaluation notes and scored using a template adapted from the Charlson comorbidity index, ${ }^{27}$ as previously reported. ${ }^{23,24}$ Prospective research protocols and the current retrospective study were approved by the Institutional Review Board of the Fred Hutchinson Cancer Research Center for the four participating institutions.

\section{Conditioning Regimen and Postgrafting Immunosuppression}

Seventy-five recipients of HLA-matched related grafts were conditioned with 2 Gy of TBI alone, ${ }^{17}$ whereas the remaining 247 related and unrelated recipients were administered 2 Gy of TBI on day 0 and fludarabine $30 \mathrm{mg} / \mathrm{m}^{2} / \mathrm{d}$ on days $-4,-3$, and -2 before HCT. ${ }^{17,20,21}$ Postgrafting immunosuppression included MMF (15 $\mathrm{mg} / \mathrm{kg}$ orally twice a day from the evening of day 0 until day +27 for related recipients or until day 40 at full dose and then tapered through day +96 for unrelated recipients $)$ and CSP $(6.25 \mathrm{mg} / \mathrm{kg}$ orally twice a day from day -3 to days 35 or 56 for related recipients or to day 100 for unrelated recipients). Seventy-nine unrelated recipients received MMF $15 \mathrm{mg} / \mathrm{kg}$ three times a day. In the absence of GVHD, CSP was tapered through days 56, 77, or 180 for related recipients and day 180 for unrelated recipients.

\section{GVHD Grading and Therapy and Supportive Care}

Diagnosis and clinical grading of GVHD were performed according to established criteria. ${ }^{28}$ Treatment was given for grade 2 to 4 acute GVHD and for extensive chronic GVHD. ${ }^{29}$ Initial

\begin{tabular}{|c|c|c|c|c|}
\hline \multirow[b]{2}{*}{ Risk Factor } & \multirow{2}{*}{$\begin{array}{c}\text { No. of } \\
\text { Patients }\end{array}$} & \multicolumn{3}{|c|}{ Failure of Progression-Free Survival (178 events) } \\
\hline & & HR & $95 \% \mathrm{Cl}$ & $P$ \\
\hline \multicolumn{5}{|l|}{ Disease risk } \\
\hline Standard & 153 & 1.0 & - & \\
\hline High & 144 & 1.7 & 1.2 to 2.3 & \\
\hline Very high & 25 & 3.2 & 2.0 to 5.2 & $<.0001$ \\
\hline \multicolumn{5}{|l|}{ Charlson comorbidity score } \\
\hline $0-2$ & 293 & 1.0 & - & \\
\hline $3+$ & 29 & 3.6 & 2.3 to 5.5 & $<.0001$ \\
\hline \multicolumn{5}{|c|}{ Tandem autologous and allogeneic HCT } \\
\hline No & 263 & 1.0 & - & \\
\hline Yes & 59 & 0.5 & 0.3 to 0.8 & .0008 \\
\hline
\end{tabular}


treatment usually consisted of prednisolone 1 to $2 \mathrm{mg} / \mathrm{kg} / \mathrm{d}$, with taper initiated within 14 days. In addition, CSP was usually resumed at full doses. Steroid-refractory acute GVHD was treated as per available investigational protocols or other salvage regimens. Treatment of chronic GVHD consisted of prednisolone $(1 \mathrm{mg} / \mathrm{kg})$ with or without alternate-day CSP. ${ }^{30}$

Standard prophylaxis against infections was used. ${ }^{31}$ Patients with chronic GVHD requiring systemic immunosuppressive therapy continued prophylaxis against Pneumocystis carinii and pneumococcal infections.

\section{Follow-Up}

Patients were examined by a healthcare provider at least three times a week for the first month and then weekly or more frequently, depending on the patient's clinical status. Diseasedependent restaging evaluations after HCT occurred monthly for the first 3 months and then at 6 months, 1 year, and yearly thereafter. For chimerism analyses, $\mathrm{T}$ cells were isolated from the peripheral blood on days $28,56,84,180$, and 365 , and then yearly after HCT. Percentages of donor-host chimerism were evaluated by fluorescent in situ hybridization for $\mathrm{X}$ and $\mathrm{Y}$ chromosomes if patients and donors were sex mismatched or by polymerase chain reaction-based amplification of variable-number tandem repeat sequences unique to donors and hosts if patients and donors were sex matched. ${ }^{32}$

\section{Treatment of Persistent, Progressive, or Relapsed Diseases and Prevention of Graft Rejection}

Persistent, progressive, or relapsed malignancies in the absence of severe manifestations of acute and chronic GVHD were treated by rapid taper and discontinuation of systemic immunosuppression to initiate GVT effects. In addition, 27 patients received $D_{L I}^{33}$ for disease relapse or progression $(n=14)$, persistent disease $(n=5)$, poor T-cell chimerism with or without persistent disease $(\mathrm{n}=7)$, and Epstein-Barr virus-lymphoproliferative disease in donor cells $(n=1)$.

\section{Statistical Methods}

Survival and progression-free survival (PFS) were estimated by the Kaplan-Meier method. Cumulative incidence estimates were calculated using methods previously described. ${ }^{34}$ Hazard ratios (HRs) were estimated from Cox regression models. Progression and nonrelapse mortality were treated as mutually competing events in the analysis of each other; death was a competing event for achieving complete remission. Patients with relapse or progression who subsequently responded to DLI or discontinuation of postgrafting immunosuppression were listed as relapsed, whereas the 13 patients who received DLI before or without experiencing progression or relapse were carried forward. For pretransplantation risk factors, multivariate models were constructed in a stepwise fashion using a threshold significance level of 0.05 for inclusion in the model. These pretransplantation factors were included in multivariate analysis of GVT effects.

Putative GVT effects were evaluated using time-dependent Cox regression models. To accommodate changes in GVHD with time after transplantation, patients were assigned to four timedependent acute GVHD comparison groups (no acute GVHD, grade 1, grade 2, and grade 3 to 4 ) and to two time-dependent chronic GVHD groups (no or limited chronic GVHD and clinical extensive chronic GVHD). All patients were considered to be in the no acute GVHD and no chronic GVHD groups on day 0 . They were then assigned to their acute GVHD group and/or their chronic GVHD group at the time of onset of each grade of acute or chronic extensive GVHD, respectively, and their subsequent probabilities of achieving complete remissions, PFS, nonrelapse mortality, and progression or relapse were compared with patients surviving a similar length of time without developing acute or chronic extensive GVHD. Graft rejection was also treated as a time-dependent covariate. Patients who experienced graft rejection were similarly assigned to a group named rejection and were compared with patients surviving a similar length of time without experiencing graft rejection. To avoid confusing the effects of rejection on impact of GVHD on GVT effects, any indicator of GVHD was dismissed at the time of graft rejection. Achievement of full (defined as $\geq 95 \%$ ) donor T-cell chimerism was also similarly treated as a time-dependent covariate. Multivariate $P$ values for a variable were based on adjustment for all other variables in the model. All $P$ values were two-sided.

Tests for a differential effect of GVHD on outcome as a function of donor status or disease risk were conducted by adding interaction terms for the time-dependent indicators of grade 2 GVHD, grade 3 GVHD, and chronic extensive GVHD. Models with and without the interaction terms were compared by likelihood ratio test.

To illustrate the effects of GVHD on subsequent events, we constructed semi-landmark plots of the cumulative incidence of progression and nonrelapse mortality. For patients with a diagnosis of acute or chronic GVHD, cumulative incidence of these events was plotted as a function of time since onset of each grade of acute GVHD and onset of extensive chronic GVHD. A landmark comparison group comprised patients who were disease free and without a diagnosis of acute GVHD at day 40 or extensive chronic GVHD at day 135; these were the median days of onset for acute and extensive chronic GVHD, respectively. Cumulative incidence for these groups was plotted as a function of time since the landmark day. For patients with grades 0,1 , or 2 acute GVHD or without extensive chronic GHVD, the incidences were conditional on remaining in the same GVHD state (ie, not having moved to a different grade or diagnosis).

\section{RESULTS}

\section{Outcomes After HCT}

Twenty-one patients rejected their grafts, whereas 301 patients had durable donor engraftment as assessed by genetic markers. The cumulative incidence of achieving full donor $(\geq 95 \%)$ T-cell chimerism is shown in Figure 1 . Grades 1, 2, 3 and 4 acute GVHD were seen in 8.1\%, 43.8\%, $10.6 \%$, and $3.4 \%$ of patients, respectively. Extensive chronic GVHD was seen in $56.2 \%$ of patients, and of these patients, $19.9 \%$ had de novo ${ }^{35}$ extensive chronic GVHD. The 3-year probability of overall survival was $49.7 \%$. The 3-year probability of PFS was 38.5\% (48.6\%, 34.2\%, and 5.9\%, respectively, for patients with standard-, high-, and very high-risk disease). In multivariate analysis, factors significantly influencing PFS included disease risk $(P<.0001)$, Charlson comorbidity score $(P<.0001)$, and tandem autologous and allogeneic $\operatorname{HCT}(P=.0008$; Table 2$)$. 


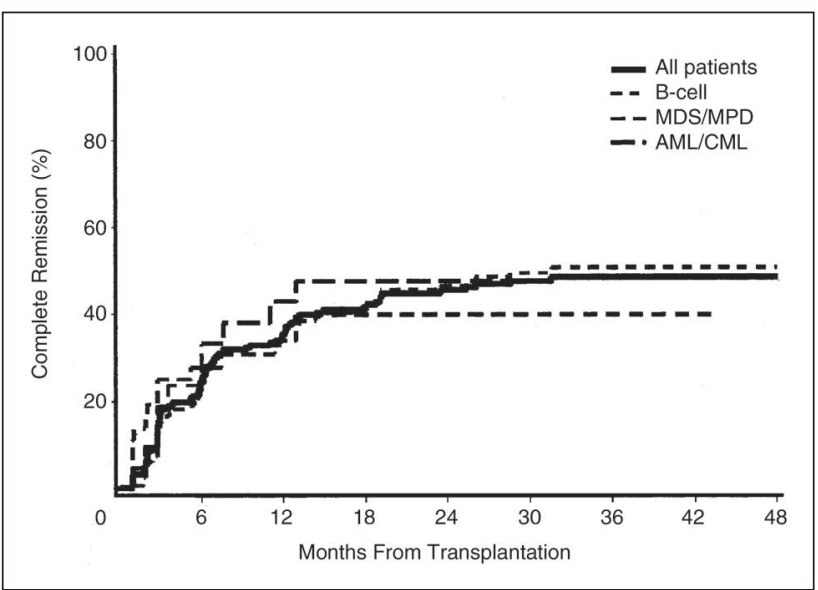

Fig 2. Cumulative incidence of achieving a complete remission in patients with measurable disease at transplantation. MDS, myelodysplastic syndrome; MPD, myeloproliferative disease; CML, chronic myeloid leukemia; AML, acute myeloid leukemia.

\section{Disease Responses in Patients With Measurable Disease at HCT}

Two hundred twenty-one of the 322 patients had measurable malignant disease before transplantation. Ninetyeight (44\%) of these patients achieved complete remissions 27 to 963 days (median, 176 days) after HCT (Fig 2), and 28 $(13 \%)$ were in partial remission at the time of analysis. Multivariate time-dependent analysis identified chemosensitivity for B-cell malignancies (HR, 2.0; 95\% CI, 1.2 to 3.2; $P=.02$ ) and tandem autologous and allogeneic HCT (HR, $0.6 ; 95 \% \mathrm{CI}, 0.3$ to $1.0 ; P=.04)$ as pretransplantation factors associated with probabilities of achieving complete remissions after HCT. After excluding patients who received tandem HCT, 76 (45\%) of 170 patients with measurable disease at HCT achieved complete remission 27 to 963 days (median, 144 days) after HCT.

\section{Impact of GVHD and Graft Rejection on Probability of Achieving Complete Remissions}

Multivariate analysis demonstrated that acute GVHD of any grade was not associated with an increased probability of achieving a complete remission (Table 3). There was a trend for a higher probability of achieving complete remissions in patients with extensive chronic GVHD $(P=.07)$, suggesting a GVT effect associated with extensive chronic GVHD. However, limited chronic GVHD was not associated with achievement of complete remissions (HR, 1.2; $95 \% \mathrm{CI}, 0.3$ to $4.1 ; P=.82$ ). There was no significant differential effect of GVHD on probability of achieving complete remissions as a function of donor status $(P=.22)$. Comparable results were obtained when tandem autologous and allogeneic HCT recipients were excluded from the analysis (Table 3 ).

\section{Impact of GVHD and Donor T-Cell Chimerism on Relapse and Progression Risk (Figs $2 A$ and $3 A$ )}

In multivariate analysis, extensive chronic GVHD was associated with a decreased risk of progression or relapse $(P=.006$; Table 4$)$. Patients with grade 1 acute GVHD tended to have less progression or relapse $(P=.07)$. Conversely, grade 2 to 4 acute GVHD did not significantly affect the risk of progression or relapse (Table 4); limited chronic GVHD also did not significantly affect the risk of progression or relapse (HR, $0.8 ; 95 \% \mathrm{CI}, 0.3$ to $2.1 ; P=.71$ ). No

Table 3. Effect of Acute and Chronic GVHD, and Graft Rejection on Probabilities to Achieve Complete Remissions in Patients With Measurable Disease at Transplantation

\begin{tabular}{|c|c|c|c|c|c|c|c|c|}
\hline \multirow[b]{3}{*}{ Factor } & \multicolumn{4}{|c|}{ All Patients ( $N=221)$} & \multicolumn{4}{|c|}{$\begin{array}{l}\text { All Patients Except for Tandem Autologous and } \\
\text { Allogeneic HCT }(n=170)\end{array}$} \\
\hline & \multirow{2}{*}{$\begin{array}{l}\text { No. of } \\
\text { Patients }\end{array}$} & \multicolumn{3}{|c|}{ Complete Remissions (98 events) } & \multirow{2}{*}{$\begin{array}{l}\text { No. of } \\
\text { Patients }\end{array}$} & \multicolumn{3}{|c|}{ Complete Remissions (76 events) } \\
\hline & & $H R^{*}$ & $95 \% \mathrm{Cl}$ & $P$ & & $\mathrm{HR} \dagger$ & $95 \% \mathrm{Cl}$ & $P$ \\
\hline \multicolumn{9}{|l|}{ Acute GVHD $\ddagger$} \\
\hline No & 82 & 1.0 & - & & 64 & 1.0 & - & \\
\hline Grade 1 & 17 & 0.7 & 0.3 to 1.7 & .47 & 10 & 0.6 & 0.2 to 1.9 & .34 \\
\hline Grade 2 & 96 & 1.1 & 0.7 to 1.7 & .72 & 75 & 1.4 & 0.8 to 2.4 & .22 \\
\hline Grade 3/4 & 26 & 1.2 & 0.6 to 2.5 & .61 & 21 & 1.7 & 0.8 to 3.6 & .18 \\
\hline \multicolumn{9}{|c|}{ Chronic GVHD, $\ddagger$ extensive } \\
\hline No & 128 & 1.0 & - & & 106 & 1.0 & - & \\
\hline Yes & 93 & 1.7 & 1.0 to 3.2 & .07 & 64 & 2.0 & 1.0 to 4.0 & .07 \\
\hline \multicolumn{9}{|l|}{ Graft rejection§ } \\
\hline No & 207 & 1.0 & - & & 156 & 1.0 & - & \\
\hline Yes & 14 & 0.3 & 0.1 to 1.5 & .14 & 14 & 0.4 & 0.1 to 1.9 & .27 \\
\hline
\end{tabular}

Abbreviations: GVHD, graft-versus-host disease; HCT, hematopoietic cell transplantation; HR, hazard ratio; CR, complete remission.

*Adjusted for disease sensitivity for B-cell malignancies and tandem autologous and allogeneic HCT.

†Adjusted for disease sensitivity for B-cell malignancies. GVHD and graft rejection were analyzed as a time-dependent risk factors.

$\ddagger$ Number of patients at risk, excluding seven and six patients with acute GVHD and 29 and 26 patients with chronic GVHD occurring after complete

remission for all patients and all patients except those who underwent tandem HCT, respectively.

§Number of patients at risk, excluding rejection occurring after CR (one patient). 


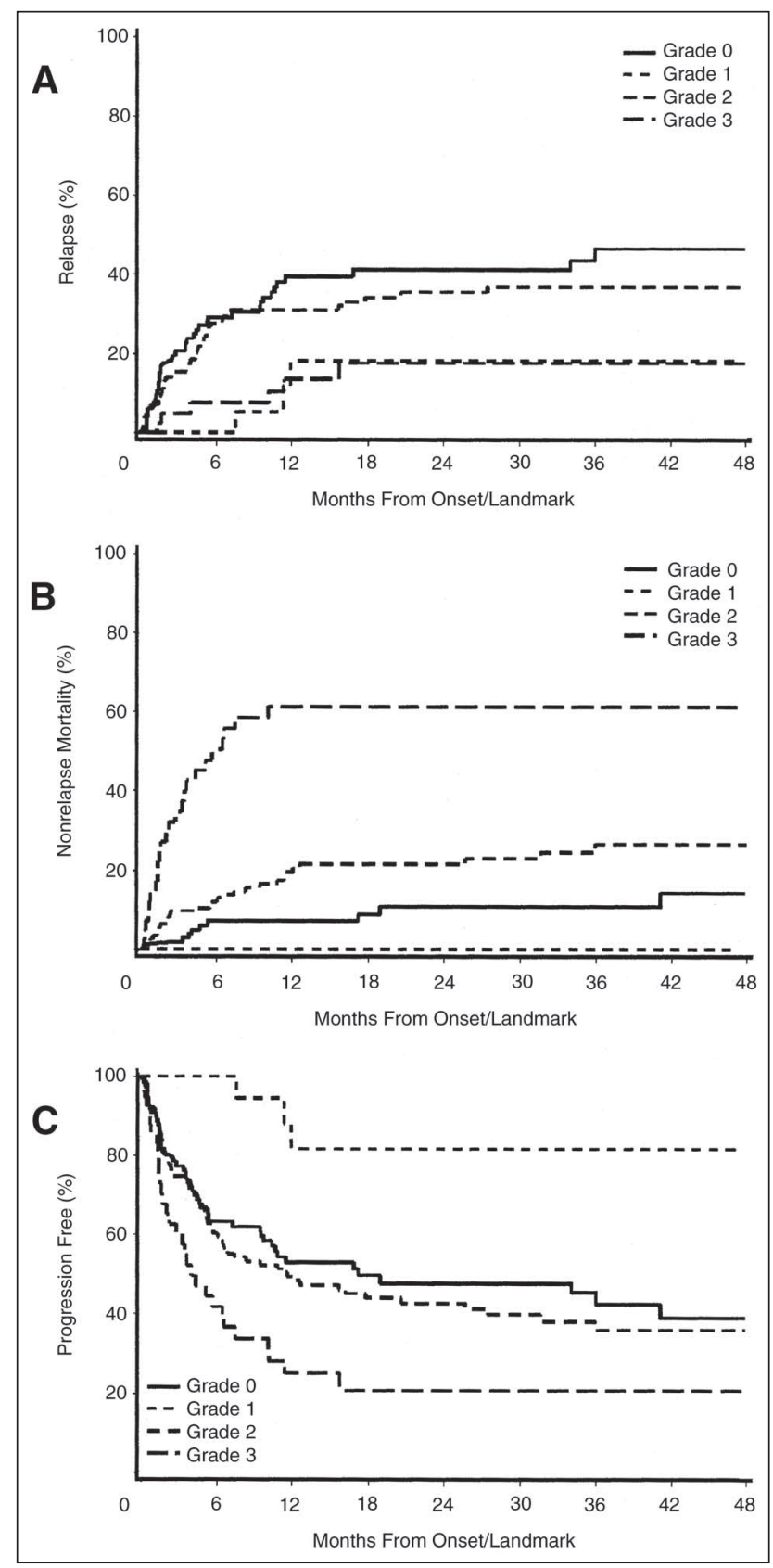

Fig 3. Semi-landmark plots illustrating impact of acute graft-versus-host disease on post-hematopoietic cell transplantation outcomes.

significant differential effect of acute and chronic GVHD on relapse or progression risk as a function of donor status $(P=.64)$ or disease group $(P=.35)$ was seen. Achievement of full donor T-cell chimerism was strongly correlated with decreased risk of progression or relapse $(P=.002)$. When separately evaluating specific disease groups, the strongest beneficial effect of extensive chronic GVHD was observed in patients with AML, MDS, and myeloproliferative disorders (excluding CML; $P=.0009$; Table 5). Similar trends were observed for patients with lymphoma and chronic lymphocytic leukemia ( $P=.12$ ), but the number of CML patients was too small to assess the impact of GVHD on disease relapse or progression.

\section{Impact of Acute GVHD and Donor T-Cell Chimerism on Nonrelapse Mortality and PFS (Figs $3 B$ and $3 C$ and 4)}

In multivariate analysis, grade 1 acute GVHD reduced the risk of nonrelapse mortality $(P=.03)$, but the number of patients in this group was quite small (Table 4$)$. Grade 2 $(P=.04)$ and grade 3 to $4(P<.0001)$ acute GVHD increased nonrelapse mortality. Interestingly, extensive chronic GVHD was not associated with an increased risk of nonrelapse mortality. There was no significant differential effect of acute and chronic GVHD on nonrelapse mortality as a function of donor status $(P=.99)$.

In multivariate analysis, grade 1 acute GVHD was associated with significantly better PFS $(P=.02)$, whereas grade 3 to 4 acute GVHD $(P<.0001)$ was associated with decreased PFS (Table 4). Extensive chronic GVHD was associated with improved PFS $(P=.003)$. The beneficial effects of extensive chronic GVHD on PFS were observed both in patients who had preceding grade 2 to 4 acute GVHD (HR, 0.5; 95\% CI, 0.3 to $0.8 ; P=.009$ ) and in patients with de novo ${ }^{35}$ extensive chronic GVHD (HR, 0.5; 95\% CI, 0.2 to $1.0 ; P=.04$ ). These associations persisted when results were analyzed separately in patients with standard-risk disease (HR, $0.4 ; 95 \% \mathrm{CI}, 0.2$ to $0.8 ; P=.01$ ) and high- or very high-risk disease (HR, 0.5; 95\% CI, 0.3 to $0.9 ; P=.02)$. No significant differential effects of acute and chronic GVHD on PFS as a function of donor status $(P=.57)$ or disease risk $(P=.58)$ were seen.

\section{DISCUSSION}

Disease responses after allogeneic HCT with nonmyeloablative conditioning are largely attributed to immunologically mediated GVT effects. The biology of these responses remains poorly defined but has been thought to involve reactions to polymorphic minor histocompatibility antigens expressed either specifically on hematopoietic cells or more widely on a number of tissue cells. ${ }^{36}$ This study sought to define GVT responses after a mild conditioning regimen of 2 Gy of TBI with or without added fludarabine and to evaluate their relationship with donor T-cell engraftment and acute and chronic GVHD. ${ }^{2,5}$ Given the risk of GVHD-associated mortality, we also investigated how those parameters affected PFS.

Historically, analyses of associations between GVHD and disease progression or relapse have posed several methodologic problems. For example, some studies did not consider patients who died or relapsed too early to develop acute or chronic GVHD and, therefore, might have overestimated the positive impacts of mild acute GVHD and of 
Table 4. Effect of Acute and Chronic GVHD and Graft Rejection on the Risks of Failure of PFS, Nonrelapse Mortality, or Progression or Relapse in 322 Patients

\begin{tabular}{|c|c|c|c|c|c|c|c|c|c|}
\hline \multirow[b]{2}{*}{ Factor } & \multicolumn{3}{|c|}{ Failure of PFS (178 events) } & \multicolumn{3}{|c|}{$\begin{array}{l}\text { Progression or Relapse } \\
\text { (108 events) }\end{array}$} & \multicolumn{3}{|c|}{ Nonrelapse Mortality* (70 events) } \\
\hline & $\mathrm{HR}+$ & $95 \% \mathrm{Cl}$ & $P$ & $\mathrm{HR} \dagger$ & $95 \% \mathrm{Cl}$ & $P$ & $\mathrm{HR} \dagger$ & $95 \% \mathrm{Cl}$ & $P$ \\
\hline \multicolumn{10}{|l|}{ Acute GVHD $\ddagger$} \\
\hline No, $n=122$ & 1.0 & - & & 1.0 & - & & 1.0 & - & \\
\hline Grade $1, n=22$ & 0.3 & 0.1 to 0.8 & .02 & 0.3 & 0.1 to 1.1 & .07 & 0.0 & - & .03 \\
\hline Grade $2, n=136$ & 1.3 & 0.9 to 1.8 & .22 & 1.0 & 0.7 to 1.6 & .91 & 2.0 & 1.0 to 4.0 & .04 \\
\hline Grade $3 / 4, n=42$ & 2.8 & 1.8 to 4.4 & $<.0001$ & 0.7 & 0.3 to 1.7 & .44 & 9.5 & 4.7 to 19 & $<.0001$ \\
\hline \multicolumn{10}{|l|}{$\begin{array}{l}\text { Chronic GVHD§ } \\
\text { (clinical extensive) }\end{array}$} \\
\hline No, $n=168$ & 1.0 & - & & 1.0 & - & & 1.0 & - & \\
\hline Yes, $n=154$ & 0.5 & 0.3 to 0.8 & .003 & 0.4 & 0.2 to 0.8 & .006 & 0.6 & 0.3 to 1.1 & .12 \\
\hline \multicolumn{10}{|l|}{ Rejection\| } \\
\hline No, $n=309$ & 1.0 & - & & 1.0 & - & & 1.0 & - & \\
\hline Yes, $n=13$ & 1.6 & 0.8 to 3.4 & .21 & 2.0 & 0.9 to 4.4 & .10 & 0.7 & 0.1 to 5.5 & .73 \\
\hline \multicolumn{10}{|c|}{$\begin{array}{l}\text { Achievement of full donor } \\
(\geq 95 \%) \text { T-cell chimerism }\end{array}$} \\
\hline No, $n=78$ & 1.0 & - & & 1.0 & - & & 1.0 & - & \\
\hline Yes, $n=244$ & 0.8 & 0.5 to 1.1 & .11 & 0.5 & 0.3 to 0.8 & .002 & 1.5 & 0.8 to 2.8 & .15 \\
\hline \multicolumn{10}{|c|}{$\begin{array}{l}\text { Abbreviations: GVHD, graft-versus-host disease; PFS, progression-free survival; HR, hazard ratio; HCT, hematopoietic cell transplantation. } \\
\text { *Fifty-three of these } 70 \text { patients with events had preceding grade } 2 \text { to } 4 \text { acute GVHD. The median time between GVHD onset and death was } 110 \text { days (range, } \\
3 \text { to } 1,096 \text { days). Causes of nonrelapse deaths in the } 70 \text { patients were infections with or without GVHD ( } \mathrm{n}=42 \text { ), GVHD without infections ( } \mathrm{n}=10 \text { ), idiopathic } \\
\text { pneumonitis ( } \mathrm{n}=4 \text { ), concurrent nonhematologic cancer }(\mathrm{n}=3 \text { ), or others ( } \mathrm{n}=11 \text { ). } \\
\text { †Effects of GVHD, graft rejection, and achievement of full donor T-cell chimerism were evaluated using time-dependent Cox regression models. Multivariate } \\
P \text { values for a variable were based on adjustment for tandem autologous and allogeneic HCT, Charlson comorbidity index score at HCT (0 to } 2,3+\text { ), and } \\
\text { disease risk (low, high, very high) in the model. All } P \text { values were two-sided. } \\
\text { łExcluded acute GVHD occurring after relapse ( } 13 \text { patients). } \\
\text { §Excluded chronic GVHD occurring after relapse ( } 24 \text { patients). } \\
\text { |Excluded rejections occurring after relapse (eight patients). }\end{array}$} \\
\hline
\end{tabular}

chronic GVHD. ${ }^{37,38}$ Other studies compared the incidences of relapse and PFS from a specific landmark time. ${ }^{39,40}$ However, landmark analyses are not ideal because patients who relapsed or did not survive to landmark cutoff were excluded from the analyses. In this study, we chose timedependent logistical regression analyses, which were similar to those reported by others, ${ }^{5}$ that included data from all patients to avoid bias from selection time points or from not considering patients who died or relapsed early.

Fifty-seven percent of patients with measurable disease at HCT responded. The delayed time to achieve complete remissions (median, 176 days) and the fact that none of the patients with graft rejection achieved sustained complete remissions were consistent with the notion that responses

\begin{tabular}{|c|c|c|c|c|c|c|c|c|c|c|c|c|}
\hline \multirow[b]{2}{*}{ Factor } & \multicolumn{3}{|c|}{$\begin{array}{l}\text { Multiple Myeloma } \\
\text { ( } \mathrm{n}=64,17 \text { events) }\end{array}$} & \multicolumn{3}{|c|}{$\begin{array}{l}\text { Lymphoma and CLL } \\
\text { ( } \mathrm{n}=129,38 \text { events) }\end{array}$} & \multicolumn{3}{|c|}{$\begin{array}{l}\text { AML, MDS, and MPD } \\
(\mathrm{n}=101,37 \text { events) }\end{array}$} & \multicolumn{3}{|c|}{$\begin{array}{c}\mathrm{CML} \\
(\mathrm{n}=18,10 \text { events) }\end{array}$} \\
\hline & $\mathrm{HR}^{*}$ & $95 \% \mathrm{Cl}$ & $P$ & $\mathrm{HR}^{*}$ & $95 \% \mathrm{Cl}$ & P & $\mathrm{HR}^{*}$ & $95 \% \mathrm{Cl}$ & $\bar{P}$ & $\mathrm{HR}^{*}$ & $95 \% \mathrm{Cl}$ & $P$ \\
\hline \multicolumn{13}{|l|}{ Acute GVHD } \\
\hline No & 1.0 & - & & & & & & & & & & \\
\hline Grade 1 & 0.3 & 0.1 to 1.1 & .07 & & & & & & & & & \\
\hline Grade 2 & 1.2 & 0.5 to 3.0 & .64 & 0.7 & 0.4 to 1.5 & .39 & 1.3 & 0.7 to 2.4 & .37 & 0.6 & 0.2 to 2.5 & .52 \\
\hline Grade 3+ & 0.6 & 0.1 to 5.3 & .67 & 0.4 & 0.1 to 1.9 & .26 & 1.2 & 0.3 to 5.1 & .81 & 2.3 & 0.3 to 17 & .42 \\
\hline \multicolumn{13}{|c|}{ Chronic GVHD } \\
\hline No & 1.0 & - & & & & & & & & & & \\
\hline Yes & 0.7 & 0.2 to 1.8 & .41 & 0.5 & 0.2 to 1.2 & .12 & 0.2 & 0.1 to 0.5 & .0009 & 1.2 & 0.2 to 7.4 & .88 \\
\hline
\end{tabular}

Abbreviations: GVHD, graft-versus-host disease; CLL, chronic lymphocytic leukemia; AML, acute myeloid leukemia; MDS, myelodysplastic syndrome; MPD, myeloproliferative disease; $\mathrm{CML}$, chronic myeloid leukemia; HR, hazard ratio; HCT, hematopoietic cell transplantation.

*Effects of GVHD were evaluated using time-dependent Cox regression models. Multivariate $P$ values for a variable were based on adjustment for tandem autologous and allogeneic HCT, Charlson comorbidity index score at HCT (0 to 2, 3+), and disease risk (low, high, very high) in the model. All $P$ values were two-sided. 


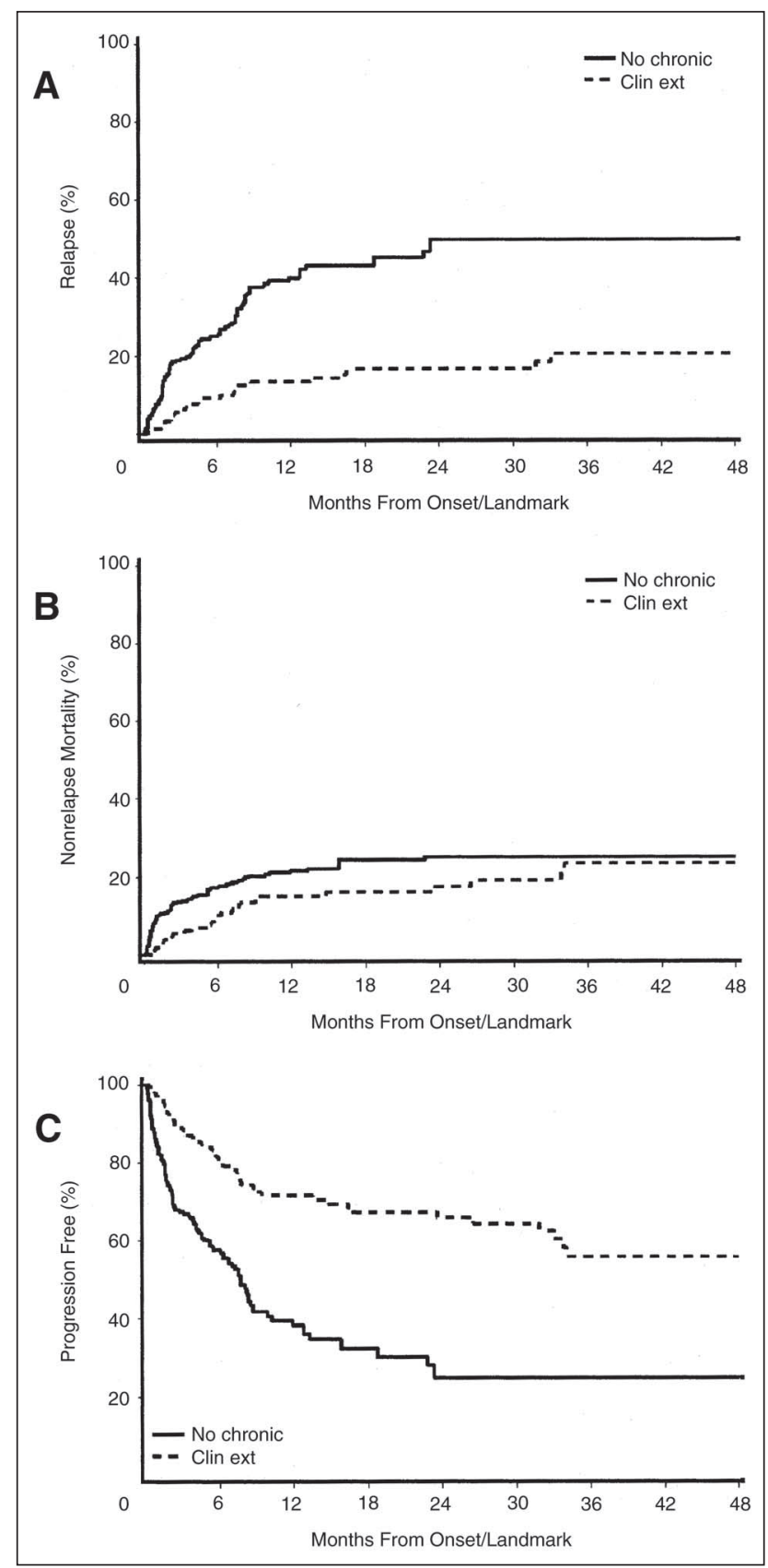

Fig 4. Semi-landmark plots illustrating impact of chronic extensive graftversus-host disease on post-hematopoietic cell transplantation outcomes. Clin Ext, clinical extensive.

were a result of GVT effects. The persistence of host antigen-presenting cells, including dendritic cells, during the first months after HCT with nonmyeloablative conditioning might, in part, be responsible for efficient donor T-cell immunization against host hematopoietic cells resulting in GVT effects. ${ }^{41}$ Strong antitumor responses were seen in some patients in the absence of clinical GVHD, suggesting that those responses were directed against antigens preferentially expressed on hematopoietic cells. ${ }^{36}$
Achievement of full donor T-cell chimerism was strongly associated with reduced risk of progression or relapse, which is possibly an expression of alloreactivity against both normal host hematopoiesis and tumor cells. However, there was also a suggestion that full donor chimerism increased nonrelapse mortality. The latter observation may be related to the apparent strong association between high levels of donor T-cell chimerism early after HCT and increased risk of grade 2 to 4 acute GVHD. ${ }^{22}$

Surprisingly, acute GVHD was not associated with an increased probability of achieving complete remissions in the current study. One explanation might be that corticosteroids and other immunosuppressive agents used to treat acute GVHD blunted GVT effects. Additionally, potential antitumor benefits of acute GVHD might have been offset by early GVHD-related mortality.

Accordingly, PFS of patients with grade 3 to 4 acute GVHD was significantly worse than the PFS of patients with grade 0 to 1 acute GVHD, and even patients with grade 2 acute GVHD showed a strong trend for worse PFS. Nonrelapse deaths occurred a median of 110 days after GVHD onset and were mainly a result of infections. ${ }^{42}$ A number of previous studies have analyzed the impact of acute GVHD in patients who underwent allogeneic HCT after myeloablative conditioning. Weiden et $\mathrm{al}^{2}$ first showed comparable survivals of leukemic patients with or without GVHD because the lessened probability of recurrent leukemia in patients with GVHD was offset by a greater probability of nonrelapse death. Significantly lower survivals were seen in patients with aplastic anemia and with various hematologic malignancies who had grade 2 to 4 acute GVHD compared with patients with grade 1 or no GVHD. ${ }^{43,44}$ Sullivan et al ${ }^{39}$ showed adverse effects of acute GVHD on survival in patients with AML in first complete remission and in patients with CML in first chronic phase but showed improved survival in patients receiving HCT for more advanced diseases. Kanda et $\mathrm{al}^{40}$ reported significantly impaired PFS in patients with grade 2 to 4 acute GVHD. A benefit of mild grade 1 acute GVHD was only seen in high-risk patients. Recently, Neudorf et $\mathrm{al}^{45}$ reported beneficial effects of grade 1 to 2 acute GVHD but detrimental effects of grade 3 to 4 acute GVHD in children with AML. Current results suggest that optimizing postgrafting immunosuppression to avoid acute GVHD requiring high-dose corticosteroids might reduce nonrelapse mortality without impairing GVT effects after nonmyeloablative conditioning.

In contrast to acute GVHD, patients with extensive chronic GVHD experienced significantly less disease progression, no increase in nonrelapse mortality, and, accordingly, improved PFS when compared with patients without extensive chronic GVHD. The beneficial effects of extensive chronic GVHD were the strongest for patients with AML and MDS, but similar trends were also observed for patients with lymphoma and chronic lymphocytic leukemia. The 
lack of an association between chronic GVHD and nonrelapse mortality, although surprising, was unlikely a result of insufficient follow-up because the median follow-up after extensive chronic GVHD onset was 12 months (range, 0 to 62 months) and was more than 2 and 3 years for 57 and 25 patients, respectively. We have previously reported that nonmyeloablative recipients with chronic GVHD were more likely to discontinue immunosuppressive therapy and less likely to die from GVHD than myeloablative recipients, which may partly explain the low nonrelapse mortality caused by chronic GVHD in our study. ${ }^{29}$ Previous reports in patients who underwent allogeneic grafts after myeloablative conditioning have also shown beneficial effects of chronic GVHD on relapse ${ }^{3,5,38,39}$ and PFS. ${ }^{3,38}$

Although acute GVHD has been identified as a major risk factor for subsequent development of chronic GVHD, ${ }^{46,47}$ several studies have shown that certain therapeutic interventions either reduced the risk of acute GVHD without changing the incidence of chronic GVHD or did not affect the level of acute GVHD while increasing the frequency of chronic GVHD. For example, in recipients of HLA-identical sibling grafts, the use of G-PBMC instead of marrow, ${ }^{48-50}$ the addition of PBMC to marrow, ${ }^{51}$ and high CD34+ cell content in the G-PBMC product $^{52}$ did not change the risk of acute GVHD, but all three interventions increased the frequency of chronic GVHD. In both related and unrelated graft recipients, substituting the combination of tacrolimus plus methotrexate for CSP plus methotrexate reduced the incidence of acute GVHD but did not change the incidence of chronic GVHD. ${ }^{53,54}$ Similar findings were made previously in two randomized studies comparing methotrexate plus CSP to either drug alone. ${ }^{55,56}$ New approaches aimed at reducing the incidence of grade 2 to 4 acute GVHD might improve PFS of allogeneic recipients after nonmyeloablative conditioning.

\section{Acknowledgment}

We thank the data coordinators Chris Davis and Heather Hildebrant and the study nurses Steve Minor, Mary Hinds, and John Sedgwick for their invaluable help in making the study possible. We also thank Bonnie Larson and Helen Crawford for help with manuscript preparation and all physicians, nurses, and support personnel for their care of patients in this study.

\section{Authors' Disclosures of Potential Conflicts of Interest}

The authors indicated no potential conflicts of interest.

\section{REFERENCES}

1. Barnes DWH, Corp MJ, Loutit JF, et al: Treatment of murine leukaemia with $\mathrm{x}$-rays and homologous bone marrow: Preliminary communication. Br Med J 2:626-627, 1956

2. Weiden PL, Flournoy N, Thomas ED, et al: Antileukemic effect of graft-versus-host disease in human recipients of allogeneic-marrow grafts. N Engl J Med 300:1068-1073, 1979

3. Weiden PL, Sullivan KM, Flournoy N, et al: Antileukemic effect of chronic graft-versus-host disease: Contribution to improved survival after allogeneic marrow transplantation. N Engl J Med 304:1529-1533, 1981

4. Maraninchi D, Gluckman E, Blaise D, et al: Impact of T-cell depletion on outcome of allogeneic bone-marrow transplantation for standardrisk leukaemias. Lancet 2:175-178, 1987

5. Horowitz MM, Gale RP, Sondel PM, et al: Graft-versus-leukemia reactions after bone marrow transplantation. Blood 75:555-562, 1990

6. Kolb HJ, Schattenberg A, Goldman JM, et al: Graft-versus-leukemia effect of donor lymphocyte transfusions in marrow grafted patients: European Group for Blood and Marrow Transplantation Working Party Chronic Leukemia. Blood 86:2041-2050, 1995

7. Collins RHJ, Shpilberg O, Drobyski WR, et al: Donor leukocyte infusions in 140 patients with relapsed malignancy after allogeneic bone marrow transplantation. J Clin Oncol 15:433-444, 1997

8. Kolb HJ, Schmidt C, Barrett AJ, et al: Graft-versus-leukemia reactions in allogeneic chimeras. Blood 103:767-776, 2004
9. Slavin S, Nagler A, Naparstek E, et al: Nonmyeloablative stem cell transplantation and cell therapy as an alternative to conventional bone marrow transplantation with lethal cytoreduction for the treatment of malignant and nonmalignant hematologic diseases. Blood 91: 756-763, 1998

10. Giralt S, Estey E, Albitar M, et al: Engraftment of allogeneic hematopoietic progenitor cells with purine analog-containing chemotherapy: Harnessing graft-versus-leukemia without myeloablative therapy. Blood 89:4531-4536, 1997

11. Khouri IF, Keating $M$, Körbling $M$, et al: Transplant-lite: Induction of graft-versus-malignancy using fludarabine-based nonablative chemotherapy and allogeneic blood progenitor-cell transplantation as treatment for lymphoid malignancies. J Clin Oncol 16:2817-2824, 1998

12. Schetelig J, Thiede $C$, Bornhauser M, et al: Evidence of a graft-versus-leukemia effect in chronic lymphocytic leukemia after reducedintensity conditioning and allogeneic stem-cell transplantation: The Cooperative German Transplant Study Group. J Clin Oncol 21:2747-2753, 2003

13. Branson K, Chopra R, Kottaridis PD, et al: Role of nonmyeloablative allogeneic stem-cell transplantation after failure of autologous transplantation in patients with lymphoproliferative malignancies. J Clin Oncol 20:4022-4031, 2002

14. Escalon MP, Champlin RE, Saliba RM, et al: Nonmyeloablative allogeneic hematopoietic transplantation: A promising salvage therapy for patients with non-Hodgkin's lymphoma whose disease has failed a prior autologous transplantation. J Clin Oncol 22:2419-2423, 2004
15. Girgis M, Hallemeier C, Blum W, et al: Chimerism and clinical outcomes of 110 unrelated donor bone marrow transplant recipients conditioned with low dose (550 cGy), single exposure total body irradiation and cyclophosphamide. Blood DOI 10.1182/blood-2003-07-2346

16. Spitzer TR, McAfee $S$, Sackstein $R$, et al: Intentional induction of mixed chimerism and achievement of antitumor responses after nonmyeloablative conditioning therapy and HLAmatched donor bone marrow transplantation for refractory hematologic malignancies. Biol Blood Marrow Transplant 6:309-320, 2000

17. McSweeney $P A$, Niederwieser $D$, Shizuru $\mathrm{JA}$, et al: Hematopoietic cell transplantation in older patients with hematologic malignancies: Replacing high-dose cytotoxic therapy with graftversus-tumor effects. Blood 97:3390-3400, 2001

18. Childs R, Chernoff A, Contentin N, et al: Regression of metastatic renal-cell carcinoma after nonmyeloablative allogeneic peripheralblood stem-cell transplantation. N Engl J Med 343:750-758, 2000

19. Childs $R$, Clave $E$, Contentin $N$, et al: Engraftment kinetics after nonmyeloablative allogeneic peripheral blood stem cell transplantation: Full donor T-cell chimerism precedes alloimmune responses. Blood 94:3234-3241, 1999

20. Maris MB, Niederwieser D, Sandmaier $B M$, et al: HLA-matched unrelated donor hematopoietic cell transplantation after nonmyeloablative conditioning for patients with hematologic malignancies. Blood 102:2021-2030, 2003

21. Niederwieser $D$, Maris $M$, Shizuru JA, et al: Low-dose total body irradiation (TBI) and fludarabine followed by hematopoietic cell 
transplantation (HCT) from HLA-matched or mismatched unrelated donors and postgrafting immunosuppression with cyclosporine and mycophenolate mofetil (MMF) can induce durable complete chimerism and sustained remissions in patients with hematological diseases. Blood 101:1620-1629, 2003

22. Baron F, Baker JE, Storb R, et al: Kinetics of engraftment in patients with hematological malignancies given allogeneic hematopoietic cell transplantation after nonmyeloablative conditioning. Blood 104:2254-2262, 2004

23. Sorror ML, Maris MB, Storer $B$, et al: Comparing morbidity and mortality of HLAmatched unrelated donor hematopoietic cell transplantation after nonmyeloablative and myeloablative conditioning: Influence of pretransplant comorbidities. Blood 104:961-968, 2004

24. Diaconescu R, Flowers CR, Storer B, et al: Morbidity and mortality with nonmyeloablative compared to myeloablative conditioning before hematopoietic cell transplantation from HLA matched related donors. Blood 104:1550-1558, 2004

25. Maloney DG, Molina AJ, Sahebi F, et al: Allografting with nonmyeloablative conditioning following cytoreductive autografts for the treatment of patients with multiple myeloma. Blood 102:3447-3454, 2003

26. Petersdorf EW, Gooley TA, Anasetti $C$, et al: Optimizing outcome after unrelated marrow transplantation by comprehensive matching of HLA class I and II alleles in the donor and recipient. Blood 92:3515-3520, 1998

27. Charlson M, Szatrowski TP, Peterson J, et al: Validation of a combined comorbidity index. J Clin Epidemiol 47:1245-1251, 1994

28. Sullivan KM: Graft-vs.-host disease, in Blume KG, Forman SJ, Appelbaum FR (eds): Thomas' Hematopoietic Cell Transplantation (ed 3). Oxford, United Kingdom, Blackwell Publishing Ltd, 2004, pp 635-664

29. Mielcarek M, Martin PJ, Leisenring W, et al: Graft-versus-host disease after nonmyeloablative versus conventional hematopoietic stem cell transplantation. Blood 102:756-762, 2003

30. Koc S, Leisenring W, Flowers MED, et al: Therapy for chronic graft-versus-host disease: A randomized trial comparing cyclosporine plus prednisone versus prednisone alone. Blood 100: 48-51, 2002

31. Junghanss $C$, Marr KA, Carter RA, et al: Incidence and outcome of bacterial and fungal infections following nonmyeloablative compared with myeloablative allogeneic hematopoietic stem cell transplantation: A matched control study. Biol Blood Marrow Transplant 8:512-520, 2002

32. Baron F, Little MT, Storb R: Kinetics of engraftment following allogeneic hematopoietic cell transplantation with reduced-intensity or nonmyeloablative conditioning. Blood Rev doi: 10.1016/j.blre.2004.06.003

33. Bethge WA, Hegenbart U, Stuart MJ, et al: Adoptive immunotherapy with donor lympho- cyte infusions after allogeneic hematopoietic cell transplantation following nonmyeloablative conditioning. Blood 103:790-795, 2004

34. Gooley TA, Leisenring W, Crowley J, et al: Estimation of failure probabilities in the presence of competing risks: New representations of old estimators. Stat Med 18:695-706, 1999

35. Wagner JL, Seidel K, Boeckh M, et al: De novo chronic graft-versus-host disease in marrow graft recipients given methotrexate and cyclosporine: Risk factors and survival. Biol Blood Marrow Transplant 6:633-639, 2000

36. Marijt WA, Heemskerk MH, Kloosterboer FM, et al: Hematopoiesis-restricted minor histocompatibility antigens HA-1- or HA-2-specific T cells can induce complete remissions of relapsed leukemia. Proc Natl Acad Sci U S A 100:2742-2747, 2003

37. Gratwohl A, Hermans J, Apperley J, et al: Acute graft-versus-host disease: Grade and outcome in patients with chronic myelogenous leukemia. Blood 86:813-818, 1995

38. Nordlander A, Mattsson J, Ringden O, et al: Graft-versus-host disease is associated with a lower relapse incidence after hematopoietic stem cell transplantation in patients with acute lymphoblastic leukemia. Biol Blood Marrow Transplant 10:195-203, 2004

39. Sullivan KM, Weiden PL, Storb $R$, et al: Influence of acute and chronic graft-versus-host disease on relapse and survival after bone marrow transplantation from HLA-identical siblings as treatment of acute and chronic leukemia. Blood 73:1720-1728, 1989

40. Kanda $Y$, Izutsu $K$, Hirai $H$, et al: Effect of graft-versus-host disease on the outcome of bone marrow transplantation from an HLAidentical sibling donor using GVHD prophylaxis with cyclosporin A and methotrexate. Leukemia 18:1013-1019, 2004

41. Mapara MY, Kim YM, Wang SP, et al: Donor lymphocyte infusions mediate superior graft-versus-leukemia effects in mixed compared to fully allogeneic chimeras: A critical role for host antigen-presenting cells. Blood 100: 1903-1909, 2002

42. Fukuda $T$, Boeckh $M$, Carter RA, et al: Risks and outcomes of invasive fungal infections in recipients of allogeneic hematopoietic stem cell transplants after nonmyeloablative conditioning. Blood 102:827-833, 2003

43. Storb R, Prentice RL, Buckner CD, et al: Graft-versus-host disease and survival in patients with aplastic anemia treated by marrow grafts from HLA-identical siblings: Beneficial effect of a protective environment. N Engl J Med 308:302307, 1983

44. Nash RA, Pepe MS, Storb R, et al: Acute graft-versus-host disease: Analysis of risk factors after allogeneic marrow transplantation and prophylaxis with cyclosporine and methotrexate. Blood 80:1838-1845, 1992

45. Neudorf S, Sanders J, Kobrinsky N, et al: Allogeneic bone marrow transplantation for children with acute myelocytic leukemia in first remission demonstrates a role for graft versus leukemia in the maintenance of disease-free survival. Blood 103:3655-3661, 2004

46. Storb $R$, Prentice RL, Sullivan KM, et al: Predictive factors in chronic graft-versus-host disease in patients with aplastic anemia treated by marrow transplantation from HLA-identical siblings. Ann Intern Med 98:461-466, 1983

47. Lee SJ, Vogelsang G, Flowers MED: Chronic graft-versus-host disease. Biol Blood Marrow Transplant 9:215-233, 2003

48. Blaise D, Kuentz M, Fortanier C, et al: Randomized trial of bone marrow versus lenograstim-primed blood cell allogeneic transplantation in patients with early-stage leukemia: A report from the Société Française de Greffe de Moelle. J Clin Oncol 18:537-571, 2000

49. Cutler C, Giri S, Jeyapalan S, et al: Acute and chronic graft-versus-host disease after allogeneic peripheral-blood stem-cell and bone marrow transplantation: A meta-analysis. J Clin Oncol 19:3685-3691, 2001

50. Bensinger WI, Martin PJ, Storer B, et al: Transplantation of bone marrow as compared with peripheral-blood cells from HLA-identical relatives in patients with hematologic cancers. N Engl J Med 344:175-181, 2001

51. Storb R, Etzioni R, Anasetti C, et al: Cyclophosphamide combined with antithymocyte globulin in preparation for allogeneic marrow transplants in patients with aplastic anemia Blood 84:941-949, 1994

52. Zaucha JM, Gooley T, Bensinger WI, et al: CD34 cell dose in granulocyte colonystimulating factor-mobilized peripheral blood mononuclear cell grafts affects engraftment kinetics and development of extensive chronic graft-versus-host disease after human leukocyte antigen-identical sibling transplantation Blood 98:3221-3227, 2001

53. Nash RA, Antin JH, Karanes $\mathrm{C}$, et al: Phase 3 study comparing methotrexate and tacrolimus with methotrexate and cyclosporine for prophylaxis of acute graft-versus-host disease after marrow transplantation from unrelated donors. Blood 96:2062-2068, 2000

54. Ratanatharathorn V, Nash RA, Przepiorka $D$, et al: Phase III study comparing methotrexate and tacrolimus (Prograf, FK506) with methotrex ate and cyclosporine for graft-versus-hostdisease prophylaxis after HLA-identical sibling bone marrow transplantation. Blood 92:23032314, 1998

55. Storb R, Deeg HJ, Farewell V, et al: Marrow transplantation for severe aplastic anemia: Methotrexate alone compared with a combination of methotrexate and cyclosporine for prevention of acute graft-versus-host disease. Blood 68:119-125, 1986

56. Storb R, Deeg HJ, Whitehead J, et al: Methotrexate and cyclosporine compared with cyclosporine alone for prophylaxis of acute graft versus host disease after marrow transplantation for leukemia. N Engl J Med 314:729 735, 1986 